\title{
The semiconducting principle of monetary and environmental values exchange
}

\author{
Quan-Hoang Vuong ${ }^{1,2 *}$ \\ The Centre for Interdisciplinary Social Research, Phenikaa University, Vietnam \\ Centre Emile Bernheim de Recherche Interdisciplinaire en Gestion, Universite Libre de Bruxelles, Belgium
}

Received: 11 November 2020

Revised: 13 January 2021

Accepted: 14 January 2021

\begin{abstract}
This short article represents the first attempt to define a new core cultural value that will enable engaging the business sector in humankind's mission to heal nature. First, I start with defining the problem of the current business culture and the extant thinking on how to solve environmental problems, which I called "the eco-deficit culture." Then, I present a solution to this problem by formulating the "semiconducting principle" of monetary and environmental values exchange, which I believe can generate "an eco-surplus business culture." This work adds one new element, the eleventh cultural value, to the ten core values of progressive cultures postulated by Harrison (2000).
\end{abstract}

Keywords: net environmental value (NEV); environment-healing element; cultural values; mindsponge

JEL Classification Codes: Q56, Q57, Q50, Q5

\section{Introduction}

Over three decades have passed since John Elkington, a leading authority on corporate sustainability and sustainable development, first presented the "triple bottom line" accounting framework under which businesses would be measured by their economic profitability, their contribution to environmental quality, and their actions toward social justice (Elkington, 1994, 1998; Jeurissen, 2000; Slaper \& Hall, 2011). In that period, countless studies have warned of the disastrous consequences of a warming Earth and put forth proposals for global sustainability (Christensen \& Olhoff, 2019; Lenton et al., 2020; Ripple et al., 2019; Steffen et al., 2015; Steffen et al., 2018). In the meantime, the three-pronged proposal has also become a prevalent benchmark in studies on sustainable business (Slaper \& Hall, 2011). What is noteworthy is, even as a growing body of work has confirmed the positive impact of corporate social responsibility (CSR) on financial performance (Ferrell, Liang, \& Renneboog, 2016; Friede, Busch, \& Bassen, 2015; Margolis, Elfenbein, \& Walsh, 2009; P, Subroto, T, \& Saraswati,

\footnotetext{
*Corresponding author. E-mail: hoang.vuongquan@phenikaa-uni.edu.vn.
}

Citation: Vuong, Q. H. (2021) The semiconducting principle of monetary and environmental values exchange, Economics and Business Letters, 10(3), 284-290.

DOI: 10.17811/ebl.10.3.2021.284-290 
2020), the debate remains on how to transform the voluntary nature of CSR into a widelypracticed mandate. This article suggests that such transformation requires approaching and dealing with environmental problems, including climate change, in an out-of-the-box manner. Along a similar vein of Elkington's multidimensional framework, I suggest moving beyond the technical fixes and conventional corporate practices toward making environmental value a core cultural value.

While the "triple bottom line" represents an important call for taking into account factors and values outside the corporate realm, its application has largely been studied under the lens of natural sciences, e.g., sustainability-related sciences, ecological economics, and ecology (Isil \& Hernke, 2017). As human activities, which include but are not limited to excessive resources consumption and carbon dioxide emissions, are the major driver of the climate crisis (Lenton et al., 2020; Ripple et al., 2019), to build a new environment-oriented core value in our culture, it is necessary to incorporate insights from the social sciences and humanities as well as participants from such disciplines. As the Chief Executive of the British Academy, Hetan Shah (2020), points out, insights from sociology, psychology, literature, philosophy, and even theology could shed new light on our understanding of environmental issues, which would subsequently change our attitude and behavior.

On the premise that to heal nature demands viable solutions as well as a renewed mindset, I believe the solution must come in the form of a new core cultural value, supplementing the thesis of "culture matters" as espoused first by Harrison and Huntington (2001). To address climate change problems in the next decades, I suggest embracing a new cultural core value centered around environmental protection. This would be the eleventh value to supplement Harrison (2000)'s list of ten values - time orientation; work and achievement; frugality; education; meritocracy; community; strict societal ethic code; justice and fair play; and secularism.

\section{On the need for reshaping our core cultural values}

The emphasis on building a culture of environmental healing and protecting values is indeed inspired by Harrison and Huntington (2001). For this reason, "culture" is not used here as an all-encompassing term, one that is defined by Taylor (1920) as a complex set of everything in society from its practices, knowledge, morals, and beliefs to institutions, custom, and law. Instead, this paper defines culture in subjective terms along the line of "values, attitudes, beliefs, orientations, and underlying assumptions prevalent among people in a society" (Huntington, 2001). Given that there is mounting evidence on the ways cultural factors shape socio-economic and political development, and thereby promoting human progress (Harrison \& Huntington, 2001; Sapolsky, 2018), I suggest refreshing our understanding of culture and its role in our long-term quest to save nature.

This call is driven by the fact that the climate crisis is accelerating at an irreversible pace despite warnings from scientists worldwide, which dated as far back as Kendall (1992) and as recent as Ripple et al. (2019). We see that, on the one hand, it is true that scientists, policymakers, and corporates have sought to bring about meaningful changes to current corporate practices, such as paying more attention to stakeholder value (Jensen, 2001) and social and environmental well-being (Elkington, 1994, 1998). On the other hand, one can argue that many such changes have not become entrenched in corporate cultures worldwide. A clear example is the inadequacy of mainstream economic textbooks in teaching climate change issues or recognizing the biases in traditional concepts such as negativities (Gills \& Morgan, 2020). Arguably, this leads to the failure to prepare future business executives to adopt or create new ways of thinking about the environment in the corporate setting. On the premise of culture being a set of subjective values, mindsets, and ideas, I argue that a core environment-centric cultural value is needed to reshape human behaviors, particularly the business sector. 
Another reason is, Elkington devises his framework of the triple bottom line without knowing the existence of digital social networks. Social media has presented a new dimension for our environmental challenges. From an institutional perspective, organizations, especially corporates, have become hyper-mediatized under the rise of social media (Hoskins \& O'Loughlin, 2015; Kaempf, 2013). Their strategic actions and plans demand appropriate media strategies. From a network perspective, today's problems such as climate change are highly politicized. Memes such as "climate change is a hoax" can spread very quickly due to the networked nature of our social media existence (Sarathchandra \& Haltinner, 2020). Such a memetic problem demands multiple remedies at a systemic and structural level. Technical and legal fixes tend to be slow to scale up; thus, they cannot be the only lever to pull. Culture is the only area where quick, adaptive changes can be made to match the challenges posed by both the infosphere and the ecosphere, where all sectors operate. As laid out in Figure 1, cultural values lie at the core all of our major problems in the world.

\section{Core cultural values re-envisioned}

The following logical diagram (Fig. 1) shows that the presence of core cultural values, as situated within cultural studies and social sciences at large, could help address the challenging global problem of climate breakdown and existential risk for humankind.

Figure 1. The logic of solving climate change problems based on a cultural value system

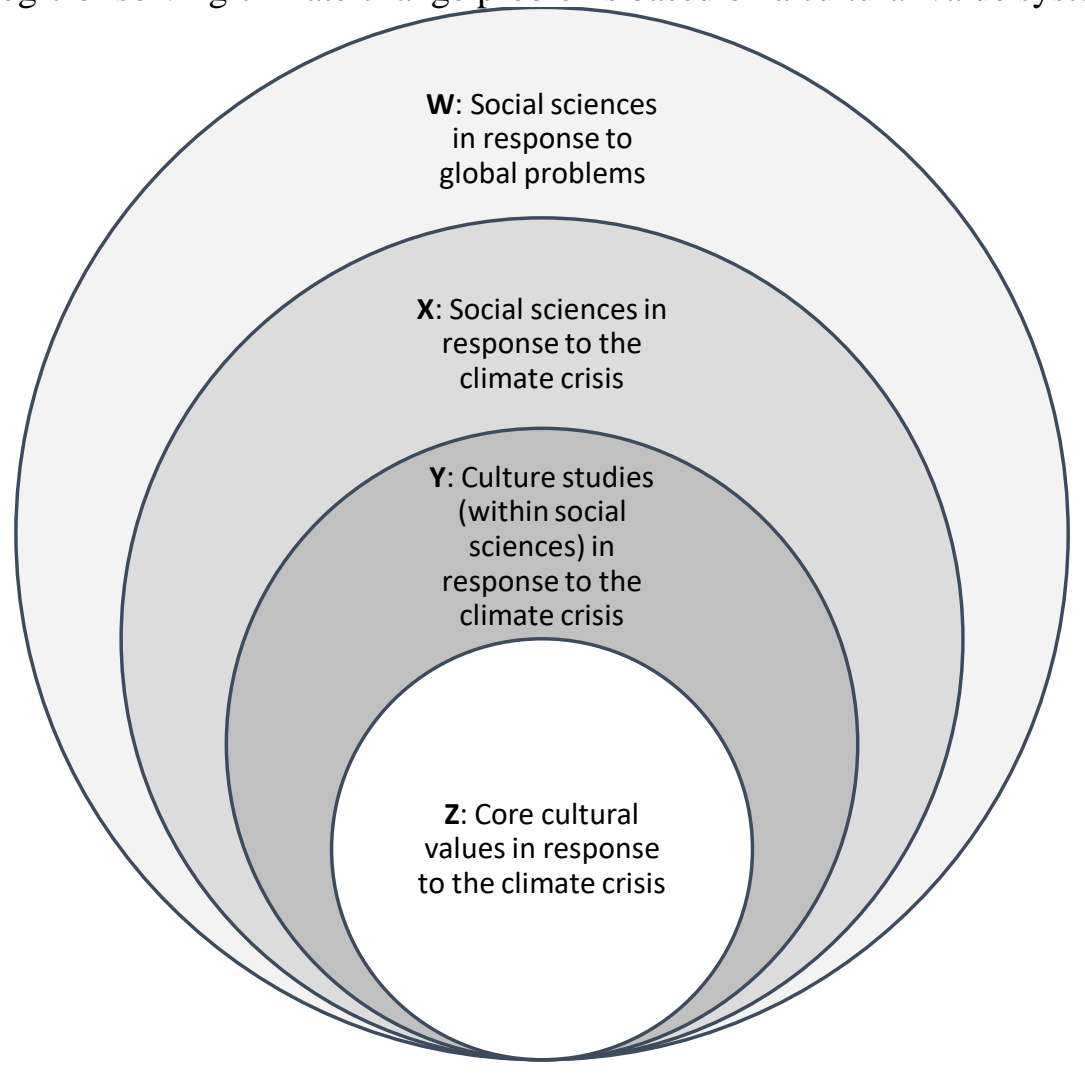

The texts in the logic diagram (Fig. 1) represent mathematical value sets, as elaborated below.

- W: The very existence of humankind requires social sciences in tackling global problems (Shah, 2020).

- X: Climate change problems constitute one of the most critical subsets of the most dangerous global problems (Victor, 2015). Therefore, solving climate change problems will need to embed social sciences in its system of equations. 
- Y: As part of social sciences, cultural research plays a crucial role in mediating society's responses to serious climate problems (Straughan \& Dixon, 2012). This gives rise to our critically important question on cultural values of adaptation to climate change and environmental sustainability (Adger, Barnett, Brown, Marshall, \& O’Brien, 2012).

- Z: According to culture studies, cultural settings not only inform and define human behaviors but also define the core values grounding such behaviors, whether they be in families, communities, or society at large. Here is where the process of mindsponge offers insights. The mindsponge model explains the underlying process of values changes in society (Vuong, 2015).

According to the modus operandi of mindsponge processes, society needs to form a consensus in establishing key cultural values, which emerge to serve the task of finding efficient cultural responses to the climate change and sustainability threats, as required by $\mathrm{Y}$, and hence, the whole system from W to Y. Here is the catch: The system of core progressive values stated and widely adopted by Lawrence E. Harrison did not provide a nature-protecting (or healing) cultural element (Harrison, 2000). In fact, this seminal work barely mentioned today's most essential keywords, such as "environment" or "nature" or "sustainability."

What happens when $Z$ turns out, actually, to be an empty set $(Z=\varnothing)$ ? It is not difficult to see that the whole system, built upon a set of zero elements, will collapse. And this is perhaps one of the main reasons why there is an increasingly louder voice, in both academia and policymaking circles, about the likely failure to deliver the promise of those Sustainable Development Goals (SDGs) dealing with the environmental problems.

\section{Business sector re-imagined}

This paper contends that the business sector holds the key to transforming core cultural values toward environmental healing. To engage the business sector in the taskforce for protecting and healing nature, improving sustainability conditions, one cannot ignore the corporate entity's raison $d$ 'être: maximizing its profitability as its "bottom-line" (Vuong, Ho, Nguyen, \& Nguyen, 2019; Vuong et al., 2021).

Fortunately, given the mindsponge modus operandi (Vuong, 2016; Vuong \& Napier, 2015), this very profitability notion can be constructed to include a cultural element that serves our purpose. That means it is time to build a new notion of profitability measured by the degree of helpfulness in healing nature and improving sustainability conditions.

So now, the net profits will have the following form:

$$
N N P=N M P+N E V,
$$

where, $N N P$ is the new notion of New Net Profits, $N M P$ the normal Net Monetary Profits, and $N E V$ the new notion of Net Environmental Value.

An emerging environment-healing business system will need to reward both types of profits. And the system will need to exhibit a feature, which I term the "semiconducting principle": the environmental value can be accounted for as a monetary one, but NOT vice versa. The current carbon trading system, for instance, has thus far lacked this very "semiconducting" property.

Here, I want to stress that the traditional philosophy or culture of the business sectors when thinking about profit is that profit equates to monetary profit. Thus, in this paradigm, a competent businessman or woman will conceive their business plan to make sure the profit is larger than the cost, which includes the payment for the "negative externalities" incurred via environmental damage (Krugman, 2010). Hence, from start to finish, such eco-deficit culture incentivizes business sectors to always strive for keeping the cost it has to pay lower than the actual damage to the environment, whether by lobbying or manipulating their tax accounts or performing green-washing campaign (Adi, 2018; Walker \& Wan, 2012), etc. We want to move away from that downward spiral of eco-deficits to a new eco-surplus culture, where the 
semiconducting principle is a norm: value created for the environment is rewarded with money, but NOT vice versa.

\section{Final remarks: The eleventh cultural value}

In 2001, Harrison and Huntington published one of the seminal works on how cultural values shape social progress and how culture has been ignored in many explanations of progress and the lack thereof. Their book concerns with how to incorporate value thinking into development. Harrison (2000) outlines ten "values, attitudes, or mindsets that distinguish progressive cultures" from the static culture. They include: time orientation; work and achievement; frugality; education; meritocracy; community; rigorous societal ethic code; justice and fair play; and secularism. Besides these values, we need to consider valuing the protection and healing of nature among defining features of a progressive culture. I call it the eleventh cultural value.

When the eleventh cultural value is adopted, our nature-healing mission can

- tap into the administrative efficiency and resourcefulness of the business sectors, whose ideas and practices must survive, evolve, and adapt in intense Darwinian market competition;

- use the vast potential of the business sector's financial management, which will do the accounting based on the formula of "profits for the environment."

Thus, businesses will

- exchange nature-nurturing value with a monetary reward, and...

- help create trust and belief in the values of regeneration and the development of natural ecosystems in the wider community.

Finally, there will be quite some work to do before this initial idea can become applicable in practice. I want to conclude some theoretical questions which can spur a research direction. First, how do we move from the current eco-deficit business culture to an eco-surplus deficit culture? Then, are there measurable thresholds for company size that entails an easier adoption of a new culture? And, how do we reimagine the education of environmental issues, especially in business and economics programs, to foster the new cultural value (Gills \& Morgan, 2020)? The challenge here is to mediate the widely accepted differences between businesses' main function of creating financial wealth for their shareholders and the expected function of making meaningful contributions to restoring ecological health. However, I trust that the presented concept could eventually benefit the current mission to save nature.

\section{References}

Adger, W. N., Barnett, J., Brown, K., Marshall, N., \& O’Brien, K. (2012). Cultural dimensions of climate change impacts and adaptation. Nature Climate Change, 3(2), 112-117. doi:10.1038/nclimate1666

Adi, A. (2018). \#Sustainability on Twitter: Loose Ties and Green-Washing CSR. In G. Grigore, A. Stancu, \& D. McQueen (Eds.), Corporate Responsibility and Digital Communities: An International Perspective towards Sustainability (pp. 99-122). Cham: Springer International Publishing.

Christensen, J., \& Olhoff, A. (2019). Lessons from a Decade of Emissions Gap Assessments. Retrieved from Nairobi:

Elkington, J. (1994). Towards the Sustainable Corporation: Win-Win-Win Business Strategies for Sustainable Development. California Management Review, 36(2), 90-100. doi:10.2307/41165746

Elkington, J. (1998). Cannibals With Forks: The Triple Bottom Line of 21 st Century Business: New Society Publishers. 
Ferrell, A., Liang, H., \& Renneboog, L. (2016). Socially responsible firms. Journal of Financial Economics, 122(3), 585-606. doi:https://doi.org/10.1016/j.jfineco.2015.12.003

Friede, G., Busch, T., \& Bassen, A. (2015). ESG and financial performance: aggregated evidence from more than 2000 empirical studies. Journal of Sustainable Finance \& Investment, 5(4), 210-233. doi:10.1080/20430795.2015.1118917

Gills, B., \& Morgan, J. (2020). Teaching climate complacency: mainstream economics textbooks and the need for transformation in economics education. Globalizations, 1-17. doi:10.1080/14747731.2020.1808413

Harrison, L. E. (2000). Culture matters. The National Interest, 60, 55-65.

Harrison, L. E., \& Huntington, S. P. (2001). Culture Matters: How Values Shape Human Progress. New York: Basic Books.

Hoskins, A., \& O'Loughlin, B. (2015). Arrested war: The third phase of mediatization. Information, communication \& society, 18(11), 1320-1338.

Huntington, S. P. (2001). Foreword: Cultures count. In L. E. Harrison \& S. P. Huntington (Eds.), Culture matters: how values shape human progress. New York: Basic Books.

Isil, O., \& Hernke, M. T. (2017). The Triple Bottom Line: A Critical Review from a Transdisciplinary Perspective. Business Strategy and the Environment, 26(8), 1235-1251. doi:10.1002/bse. 1982

Jensen, M. C. (2001). Value maximization, stakeholder theory, and the corporate objective function. Journal of Applied Corporate Finance, 14(3), 8-21. doi:https://doi.org/10.1111/j.1745-6622.2001.tb00434.x

Jeurissen, R. (2000). [Cannibals with Forks: The Triple Bottom Line of 21st Century Business, John Elkington]. Journal of Business Ethics, 23(2), 229-231.

Kaempf, S. (2013). The mediatisation of war in a transforming global media landscape. Australian Journal of International Affairs, 67(5), 586-604.

Kendall, H. (1992). World Scientists' Warning to Humanity. Retrieved from https://www.ucsusa.org/sites/default/files/attach/2017/11/World\%20Scientists\%27\%20Wa rning\%20to\%20Humanity\%201992.pdf

Krugman, P. (2010). Building a Green Economy. New York Times. Retrieved from https://www.nytimes.com/2010/04/11/magazine/11Economy-t.html

Lenton, T. M., Rockström, J., Gaffney, O., Rahmstorf, S., Richardson, K., Steffen, W., \& Schellnhuber, H. J. (2020). Climate tipping points too risky to bet against. Nature, 575, 592595.

Margolis, J. D., Elfenbein, H. A., \& Walsh, J. P. (2009). Does it Pay to Be Good...And Does it Matter? A Meta-Analysis of the Relationship between Corporate Social and Financial Performance Retrieved from Available at SSRN: https://ssrn.com/abstract=1866371 or http://dx.doi.org/10.2139/ssrn.1866371

P, G. K., Subroto, B., T, S., \& Saraswati, E. (2020). Explaining the complexity relationship of CSR and financial performance using neo-institutional theory. Journal of Asian Business and Economic Studies, 27(3), 227-244. doi:10.1108/JABES-10-2019-0106

Ripple, W., Wolf, C., Newsome, T., Barnard, P., Moomaw, W., \& Grandcolas, P. (2019). World scientists' warning of a climate emergency. BioScience, 70(1), 8-12.

Sapolsky, R. (2018). Behave: The Biology of Humans at Our Best and Worst. London: Vintage. Sarathchandra, D., \& Haltinner, K. (2020). How Believing Climate Change is a "Hoax" Shapes Climate Skepticism in the United States. Environmental Sociology, 1-14. doi: 10.1080/23251042.2020.1855884

Shah, H. (2020). Global problems need social science. Nature, 577(7790), 295-295. doi:10.1038/d41586-020-00064-X

Slaper, T. F., \& Hall, T. J. (2011). The triple bottom line: What is it and how does it work. Indiana Business Review, 86(1), 4-8. 
Steffen, W., Richardson, K., Rockström, J., Cornell, S. E., Fetzer, I., Bennett, E. M., . . Sörlin, S. (2015). Planetary boundaries: Guiding human development on a changing planet. Science, 347(6223), 1259855. doi:10.1126/science. 1259855

Steffen, W., Rockström, J., Richardson, K., Lenton, T. M., Folke, C., Liverman, D., . . . Schellnhuber, H. J. (2018). Trajectories of the Earth System in the Anthropocene. Proceedings of the National Academy of Sciences, 115(33), 8252-8259. doi:10.1073/pnas.1810141115

Straughan, E., \& Dixon, D. (2012). Cultural response to climate change. Nature Climate Change, 2(7), 480-481. doi:10.1038/nclimate1593

Taylor, E. (1920). Primitive Culture (repr. ed.). New York: J. P. Putnam's Sons.

Victor, D. (2015). Climate change: Embed the social sciences in climate policy. Nature, 520(7545), 27-29. doi:10.1038/520027a

Vuong, Q.-H., Ho, M.-T., Nguyen, H.-K. T., \& Nguyen, M.-H. (2019). The trilemma of sustainable industrial growth: evidence from a piloting OECD's Green city. Palgrave Communications, 5(1). doi:10.1057/s41599-019-0369-8

Vuong, Q.-H., La, V.-P., Nguyen, H.-K. T., Ho, M.-T., Vuong, T.-T., \& Ho, M.-T. (2021). Identifying the moral-practical gaps in corporate social responsibility missions of Vietnamese firms: An event-based analysis of sustainability feasibility. Corporate Social Responsibility and Environmental Management, 28(1), 30-41. doi:https://doi.org/10.1002/csr.2029

Vuong, Q. H. (2015). Be rich or don't be sick: estimating Vietnamese patients' risk of falling into destitution. SpringerPlus, 4(1), 529. doi:10.1186/s40064-015-1279-x

Vuong, Q. H. (2016). Global Mindset as the Integration of Emerging Socio-Cultural Values Through Mindsponge Processes. In J. Kuada (Ed.), Global Mindsets: Exploration and Perspectives (pp. 109-126). New York: Routledge.

Vuong, Q. H., \& Napier, N. K. (2015). Acculturation and global mindsponge: An emerging market perspective. International Journal of Intercultural Relations, 49, 354-367. doi:10.1016/j.ijintrel.2015.06.003

Walker, K., \& Wan, F. (2012). The harm of symbolic actions and green-washing: Corporate actions and communications on environmental performance and their financial implications. Journal of Business Ethics, 109(2), 227-242. 